Tropical Journal of Pharmaceutical Research February 2017; 16 (2): 439-443

ISSN: $1596-5996$ (print); 1596-9827 (electronic) (c) Pharmacotherapy Group, Faculty of Pharmacy, University of Benin, Benin City, 300001 Nigeria.

All rights reserved.

Available online at http://www.tjpr.org Original Research Article

http://dx.doi.org/10.4314/tjpr.v16i2.24

\title{
A study on the expression levels of matrix metalloproteinases and their inhibitors in patients with ulcerative colitis
}

\author{
Guo-Dong Huang ${ }^{1}$ and Jing Xiong ${ }^{2 *}$ \\ ${ }^{1}$ Department of Integrated Traditional Chinese Medicine and Western Medicine, ${ }^{2}$ Cadre's Ward, The First Affiliated Hospital of \\ Nanchang University, Nanchang, 330006, Jiangxi, China
}

*For correspondence: Email: xiongjing328@hotmail.com; Tel/Fax: 0086-791-88692962

Received: 11 May 2016

Revised accepted: 30 December 2016

\begin{abstract}
Purpose: To investigate the expression matrix metalloproteinases (MMPs) and tissue inhibitors of metalloproteinases (TIMPs) in ulcerative colitis (UC) patients admitted to The First Affiliated Hospital of Nanchang University, Nanchang, Jiangxi, China.

Methods: The expression of MMPs and TIMPs) was evaluated in 50 patients (36 males, 14 females) with UC who were admitted to The First Affiliated Hospital of Nanchang University, Nanchang, 330006, Jiangxi, China. Tissue samples obtained from core needle biopsies were evaluated using immunochemistry techniques.

Results: MMP-9 and TIMP-1 were strongly expressed in the glandular epithelium and inflammatory cells. In addition, the expression was coupled with changes in the tissue architecture and inflammation in the lamina propria. The expression of MMPs and weak activation of their inhibitors was related to UC progression. There were significant correlations between MMP expression and histopathological parameters $(p=0.051, R=0.392)$. MMP expression correlated with weaker expression of TIMPs $(p=$ $0.032, R=0.0581)$

Conclusion: MMP-2, MMP-7, and MMP-9 are potential targets for therapeutic control of UC.
\end{abstract}

Keywords: Glandular epithelium, Inflammatory cells, Inhibitors, Matrix metalloproteinases (MMPs), Tissue inhibitors of metalloproteinases, Ulcerative colitis

Tropical Journal of Pharmaceutical Research is indexed by Science Citation Index (SciSearch), Scopus, International Pharmaceutical Abstract, Chemical Abstracts, Embase, Index Copernicus, EBSCO, African Index Medicus, JournalSeek, Journal Citation Reports/Science Edition, Directory of Open Access Journals (DOAJ), African Journal Online, Bioline International, Open-J-Gate and Pharmacy Abstracts

\section{INTRODUCTION}

Ulcerative colitis (UC) is a chronic inflammatory bowel disease that usually causes inflammation in the large intestine [1]. As an autoimmune disease, UC is influenced by environmental and genetic factors [2] and causes ulcers and inflammation in the colon [3]. The incidence of UC has increased gradually in recent years [4]; symptoms include bloody diarrhoea, fever, abdominal pain, and weight loss [5]. The pathogenesis of the disease is not fully understood, but a genetic risk is presumed [6].
The treatment of UC includes anti-inflammatory drugs and therapy targeted to the immune response $[7,8]$.

Matrix metalloproteinases (MMPs) are proteolytic calcium-dependent enzymes that contain zinc and belong to the metzincin superfamily $[9,10]$. These enzymes play an important role in the degradation of extracellular matrix protein by cleaving its components [11]. 
MMPs are also involved in cell proliferation, adhesion, differentiation, and dispersion, and programed cell death [12]. Excreted by endothelial cells, neutrophils, macrophages, neutrophils, and lymphocytes [13,14], MMPs are controlled by tissue inhibitors of metalloproteinases (TIMPs) [15]. The balance between MMPs and TIMPs must be controlled to maintain and remodel cells and tissues. Imbalances in these proteins can lead to diseases such as tissue fibrosis, cardiovascular diseases, ulcers, and inflammation [15].

In this study, we evaluated the immunohistochemical associations of MMPs and TIMPS, specifically MMP-2, MMP-7, and MMP-9 and TIMP-1 and TIMP-2, respectively, in 50 patients with UC and their correlations with histochemical and pathological parameters. Increased understanding of the expression of these proteins in UC could provide novel therapeutic targets.

\section{METHODS}

The study complied with National Institutes of Health guidelines [16] and was approved by Bioethics Committee of The First Affiliated Hospital of Nanchang University, Nanchang, Jiangxi, China (ref no. NU/FAH/BioEt/2014-16A).

The study enrolled 50 patients (36 males, 14 females) diagnosed with UC. All of the patients were older than 21 years of age. Core needle biopsy samples embedded in paraffin were obtained from the Department of Gastroenterology and Surgery, Chinese Central Hospital.

All of the reagents were purchased from Novocastra Reagents (Leica Microsystems, Germany), including rabbit anti-Smad4, rabbit anti-Smad6, and rabbit anti-Smad7 monoclonal antibody for the MMPs and mouse monoclonal antibody for TIMP-1 and -2 . All of the sections examined were counterstained with haematoxylin and eosin (H\&E) before histopathological evaluation.

The formalin-fixed tissue specimens embedded in paraffin were cut into 4$\mu \mathrm{m}$-thick sections using a HM 450 sliding microtome (Thermo Fisher Scientific, USA). The sections were deparaffinised in xylene and rehydrated with alcohol. The sections examined for MMP-2 and TIMP-1 were placed in a microwave oven for $30 \mathrm{~min}$, treated with citrate buffer, and then subjected to antigen retrieval using a pressure chamber. Slides were incubated with the primary antibodies for MMP-2, MMP-7, MMP-9, TIMP-1, and TIMP-2, diluted 1:70, and kept overnight at $4{ }^{\circ} \mathrm{C}$. Then, they were incubated for $20-30 \mathrm{~min}$ in amplifying reagent at room temperature. The resulting antigen-antibody complex activity was detected and visualised using diaminobenzidine (DAB), and the specimen was counterstained with haematoxylin.

\section{Statistical analysis}

Statistical analysis was carried out using SPSS 16.0 (SPSS, USA). Student's $t$-test was used to compare the different groups and the correlations between parameters were calculated using Spearman's rank correlation. $P<0.05$ was considered statistically significant.

\section{RESULTS}

Of the 50 patients with UC studied, acute, moderate, indefinite, and no epithelial dysplasia was found in 4, 14, 20, and 12 patients, respectively (Table 1). Evaluating the UC disease activity using the protocol developed by Geboes et al [17], 30 subjects had chronic UC, 8 were active cases, and 12 subjects had inactive UC (Table 1).

Table 1: Gender, grade of dysplasia and disease activity in the investigation

\begin{tabular}{ccccccccc}
\hline \multicolumn{2}{c}{ Sex (N) } & \multicolumn{4}{c}{ Grade of dysplasia $\mathbf{( N )}$} & \multicolumn{3}{c}{ Disease activity (N) } \\
\hline Female & Male & Nil & Indefinite & Moderate & Acute & Inactive & Active & Chronic \\
\hline 14 & 36 & 12 & 20 & 14 & 4 & 12 & 8 & 30 \\
\hline
\end{tabular}


Note: $\mathrm{N}$ denotes number

Table 2: MMP-2, MMP-7, and MMP-9 expression in glandular and inflammatory cells

\begin{tabular}{|c|c|c|c|c|c|c|c|c|}
\hline \multirow{3}{*}{$\begin{array}{l}\text { Protein } \\
\text { expression }\end{array}$} & \multicolumn{8}{|c|}{ Ulcerative colitis (UC) } \\
\hline & \multicolumn{4}{|c|}{ Glandular cells ( $\%$ of cases) } & \multicolumn{4}{|c|}{ Inflammatory cells ( $\%$ of cases) } \\
\hline & $\begin{array}{c}\text { Not } \\
\text { present }\end{array}$ & Weak & Average & Strong & $\begin{array}{c}\text { Not } \\
\text { present }\end{array}$ & Weak & Average & Strong \\
\hline MMP-2 & $2(4 \%)$ & $36(72 \%)$ & $8(16 \%)$ & $4(8 \%)$ & $8(16 \%)$ & $36(72 \%)$ & $5(10 \%)$ & $1(2 \%)$ \\
\hline MMP-7 & $29(58 \%)$ & $11(22 \%)$ & $9(9)$ & $1(2 \%)$ & $3(6 \%)$ & $18(36 \%)$ & $16(32 \%)$ & $13(26 \%)$ \\
\hline MMP-9 & $4(8 \%)$ & $16(32 \%)$ & $11(22 \%)$ & $19(38 \%)$ & $2(4 \%)$ & $16(32 \%)$ & $13(26 \%)$ & $19(38 \%)$ \\
\hline
\end{tabular}

Examining glandular cells, the MMP-2 expression was weak in the glandular epithelium of 50 cases, covering $73.3 \%$ of the patients with UC and in inflammatory cells in $72 \%$ of the cases. MMP-2 expression in the glandular tubes was average and strong in 16 and $8 \%$ of the cases, respectively, compared with 10 and $2 \%$ of the inflammatory cells (Table 2).

In comparison, no MMP-7 expression was seen in the glandular epithelium of 29 patients (58\%), compared with $6 \%$ of the inflammatory cells. There was weak expression in the glandular cells of $22 \%$ of the cases, compared with $36 \%$ of the inflammatory cells. MMP-9 expression was weak in both the glandular and inflammatory cells in $16 \%$ of the cases; average expression of both was observed in $32 \%$ of the cases (Figure 1 and Table 2).

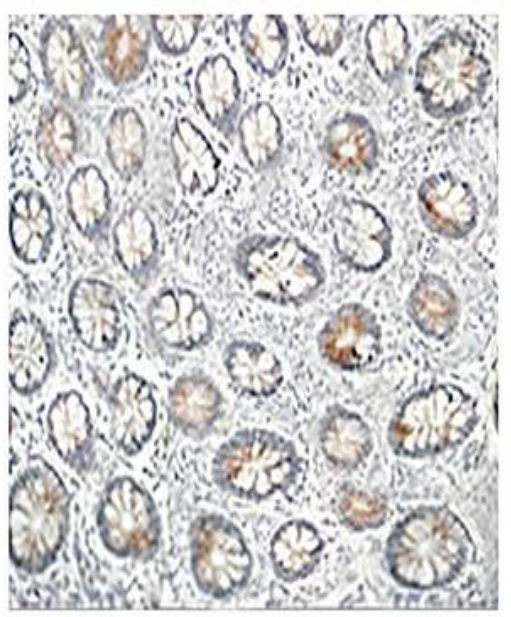

(a)

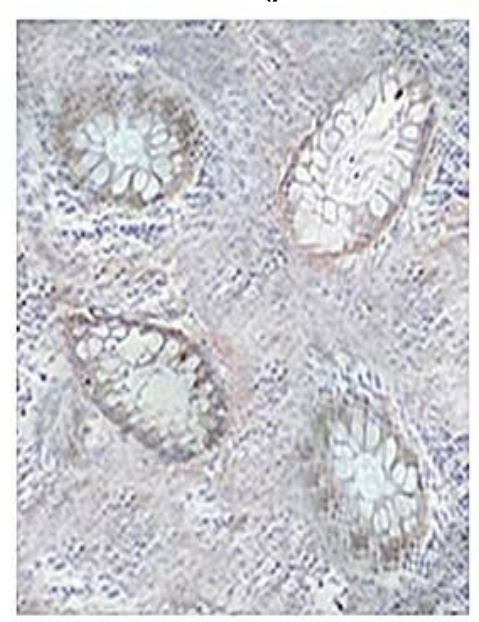

(b)
Strong TIMP-1 expression was found in the glandular epithelium in 32 cases $(64$ $\%$ ) and in $40 \%$ of the inflammatory infiltrate cells. There was weak TIMP-2 in glandular epithelium in $44 \%$ of the cases, compared with $33 \%$ of the inflammatory cells (Figure 2a, b).

There was a strong correlation between the expression of MMPs in the glandular epithelium and the presence of ulcers ( $p=0.051, R=0.392$ ). In addition, MMP2 in the glandular epithelium tended to be correlated with a change in the tissue architecture $(p=0.076, R=0.381)$ and the presence of neutrophils in the lamina propria ( $p=0.077, R=0.371)$ (Fig. 1a).

The expression of MMP-7 in the glandular epithelium was correlated with erosions $\quad(p=0.031, \quad R=0.492)$. Decreased MMP-9 expression was observed with altered tissue architecture $(p=0.067, R=-0.392)$ (Fig. 1b, c).

Figure 1: Immunohistochemical expression of (a) MMP-2, (b) MMP-7 and (c) MMP-9 in glandular epithelium and inflammatory cells 


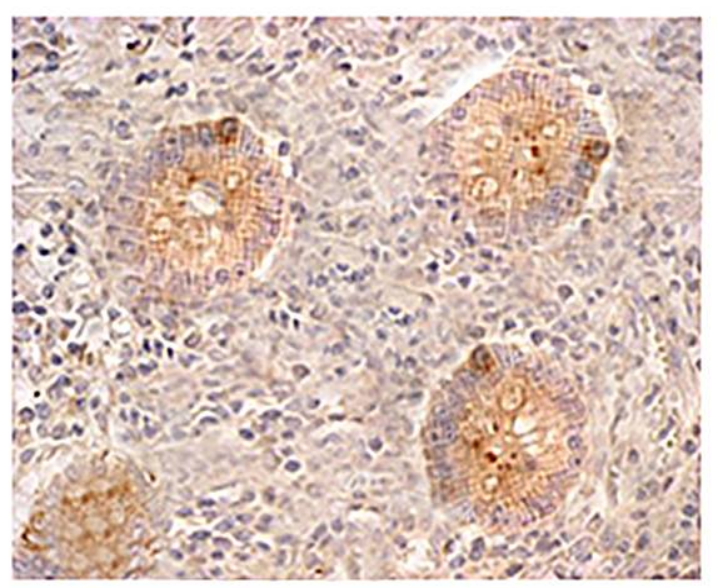

(a)

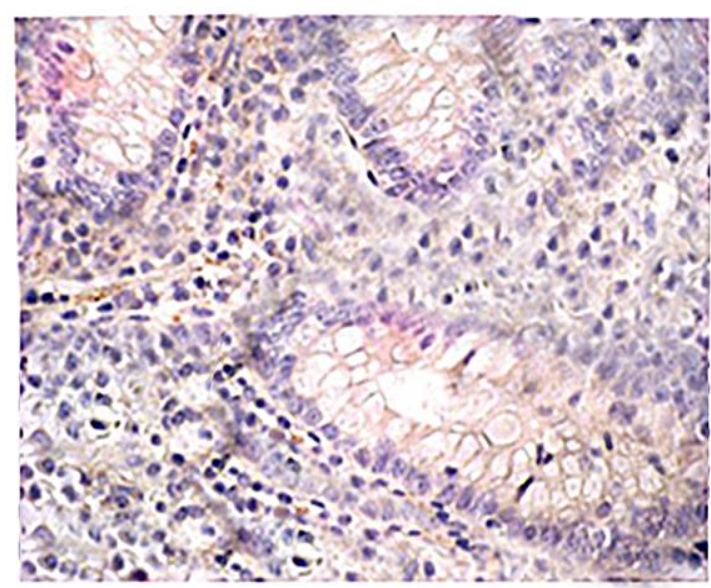

(b)

Figure 2: Immunohistochemical expression of (a) TIMP-1 and (b) TIMP-2 in glandular epithelium and inflammatory cells

The expression of MMP-2 in the lamina propria was correlated with the presence of neutrophils in an inflammatory infiltrate. In addition, the expression TIMP-1 correlated with eosinophils in the lamina propria $(p=0.024, \quad R=0.612)$ and neutrophils in the glandular epithelium $(p=0.032, \quad R=0.0581)$. There was a significant correlation with the expression of TIMP-2 in the glandular epithelium, but not with inflammatory cells (Figure 2a, b).

\section{DISCUSSION}

The expression of various metalloproteinases and their inhibitors observed in the patients with UC was related to the stage of the disease. There was weak MMP-7 expression in the glandular epithelium in $60 \%$ of the cases with an inflammatory infiltrate. Weak MMP-2 expression was observed in the inflammatory infiltrate contrasting strong expression in the glandular epithelium, as noted by von Lampe et al [18]. MMP-2 expression was associated with erosions in the glandular epithelium. The expression of MMP-2 was also mainly associated with mesenchymal cells and neutrophils in the glandular epithelium and an inflammatory infiltrate. MMP-9 expression was observed in both the glandular epithelium and inflammatory infiltrate, as reported in patients with UC [19]. In addition, the protein activity in UC increased with the homogeneity of the inflamed mucosa.

The tissue architecture of the colon changed with the level of MMP-9 expression, implying that MMP-9

expression plays a role in the chronic inflammation of the tissue lining of the colon and remodelling of the tissue architecture. Our results revealed that MMP-9 plays a crucial role in the pathogenesis of UC, as reported elsewhere [20,21], suggesting MMP-9 as a potential target for treatment. TIMP-1 and TIMP-2 also play vital roles in regulating the activity of MMPs and maintaining equilibrium. The expression of TIMP-1 in an inflamed ulcer in UC has been reported [22].

\section{Limitation of the study}

One limitation of this study is that the tissue samples were from a Chinese population; the correlation between the expression of MMPs and TIMPs may vary in other populations of patients with UC.

\section{CONCLUSION}

The expression of MMPs and their inhibitors reflects UC progression. There are significant correlations between MMPs and histopathological parameters. MMP-2, MMP-7 and MMP-9 are potential targets for reducing the progression of UC in patients by using inhibitors such as TIMP-1 and TIMP-2.

\section{DECLARATIONS}

\section{Conflict of Interest}

No conflict of interest associated with this work. 


\section{Contribution of Authors}

The authors declare that this work was done by the authors named in this article and all liabilities pertaining to claims relating to the content of this article will be borne by them.

\section{Open Access}

This is an Open Access article that uses a funding model which does not charge readers or their institutions for access and distributed under the terms of the Creative Commons Attribution License (http://creativecommons.org/licenses/by 14.0) and the Budapest Open Access Initiative (http://www.budapestopenaccessinitiative.org/rea d), which permit unrestricted use, distribution, and reproduction in any medium, provided the original work is properly credited.

\section{REFERENCES}

1. Podolsky DK. Inflammatory bowel disease. N. Engl. J. Med. 2002; 347(6): 417-429.

2. Talley NJ, Abreu MT, Achkar JP, American College of Gastroenterology IBD Task Force. An evidence-based systematic review on medical therapies for inflammatory bowel disease. Am. J. Gastroenterol. 2011; 106: S2S25.

3. Pardi DS, Kelly CP. Microscopic colitis. Gastroenterol. 2011; 140(4): 1155-1165.

4. Jiang XL, Cui HF. An analysis of 10218 ulcerative colitis cases in China. World J. Gastroenterol. 2002; 8(1): 158161.

5. Sawczenko A, Sandhu BK. Presenting features of inflammatory bowel disease in Great Britain and Ireland. Arch. Dis. Child. 2003; 88(1): 995-1000.

6. Hanauer SB, Sandborn W. Management of Crohn's disease in adults. Am. J. Gastroenterol. 2001; 96(3): 635-643.

7. Langan RC, Gotsch $P B$, Krafczyk MA, Skillinge $D D$. Ulcerative colitis: diagnosis and treatment. Am. Fam. Physician. 2007; 76(9): 1323-1330.

8. Baumgart DC, Sandborn WJ. Inflammatory bowel disease: clinical aspects and established and evolving therapies. The Lancet. 2007; 369(9573): 1641-1657.

9. Verma RP, Hansch C. Matrix metalloproteinases (MMPS): chemical-biological functions and (Q)SARs. Bioorg. Med. Chem. 2007; 15(6): 2223-2268.

10. Van LP, Libert $C$. Chemokine and cytokine processing by matrix metalloproteinases and its effect on leukocyte migration and inflammation. J. Leukoc. Biol. 2007; 82(6): 1375-1381.

11. Eisen A, Jeffrey J, Gross J. Human skin collagenase. Isolation and mechanism of attack on the collagen molecule. Biochim. Biophys. Acta. 1968; 151(3): 637645.

12. Gross J, Lapiere CM. Collagenolytic activity in amphibian tissues: a tissue culture assay". Proc. Natl. Acad. Sci. U $S$ A. 1962; 48(6): 1014-1022.

13. Pei D, Kang $T, Q i \quad H$. Cysteine array matrix metalloproteinase (CA-MMP)/MMP-23 is a type II transmembrane matrix metalloproteinase regulated by a single cleavage for both secretion and activation. J. Biol. Chem. 2000; 275(43): 33988-33997.

14. Trexler M, Briknarová K, Gehrmann M, Llinás M, Patthy $L$. Peptide ligands for the fibronectin type II modules of matrix metalloproteinase 2 (MMP-2). J. Biol. Chem. 2003; 278(14): 12241-12246.

15. Trojanek J. Matrix metalloproteinases and their tissue inhibitors. Postepy. Biochem. 2012; 58(3): 353-362.

16. www.osp.od.nih.gov/sites/default/files/NIH_Guidelines.ht $\mathrm{ml}$

17. Geboes K, Riddell R, Ost A, Jensfelt $B$, Persson $T$, Löfberg $R$. A reproducible grading scale for histological assessment of inflammation in ulcerative colitis. Gut. 2000; 47(3): 404-409.

18. von Lampe B, Barthel B, Coupland SE, Riecken EO, Rosewicz S. Differential expression of matrix metalloproteinases and their tissue inhibitors in colon mucosa of patients with inflammatory bowel disease. Gut. 2000; 47(1): 63-73.

19. Mao JW, He XM, Tang HY, Wang YD. Protective role of metalloproteinase inhibitor (AE-941) on ulcerative colitis in rats. World J. Gastroenterol. 2012; 18(47): 70637069.

20. Medina C, Videla S, Radomski A, Radomski MW, Antolín $M$, Guarner F, Vilaseca J, Salas A, Malagelada JR. Increased activity and expression of matrix metalloproteinase-9 in a rat model of distal colitis. Am. J. Physiol. Gastrointest. Liver Physiol. 2003; 284(1): G116-G122.

21. Naito $Y$, Takagi T, Kuroda M. Katada K, Ichikawa $H$, Kokura S, Yoshida N, Okanoue T, Yoshikawa T. An orally active matrix metalloproteinase inhibitor, ONO4817, reduces dextran sulfate sodium-induced colitis in mice. Inflamm. Res. 2004; 53(9): 462-468.

22. Wang YD, Yan PY. Expression of matrix metalloproteinase-1 and tissue inhibitor of metalloproteinase-1 in ulcerative colitis. World J. Gastroenterol. 2006; 12(37): 6050-6053. 